Reference: Rosa, Alexandra Assis and Huang Guowen. 2016. "Translation across Time in East and West Encounters: An Overview." East and West Encounters: Translation in Time. Special Issue of Journal of World Languages. Ed. Alexandra Assis Rosa, Huang Guowen. 3 (1). 1-4.

Notice: This article is here reproduced in its preprint version (authors submitted revised version 2015). It is under copyright and the publisher should be contacted for permission to re-use or reprint the material in any form.

\title{
Translation Across Time in East and West Encounters: An Overview
}

Alexandra Assis Rosa, Faculdade de Letras, Universidade de Lisboa

Huang Guowen, College of Foreign Studies, South China Agricultural University

This special issue addresses topics related to translation history, historiography and metahistoriography in East and West encounters. It thereby merges a temporal and spatial perspective and wishes to contribute to the understanding of why, how and for which purposes translation history matters. It accordingly encompasses reflections on main issues in translation history, on current and future projects to map translation, as well as on translation and its conceptualization across time, with a special emphasis on East and West encounters and dialogues.

As stated by Lieven D'hulst (2010), the coupling of translation and history allows the study from at least two main different angles. The first one focuses on how translation can help understand the history of cultural practices; the second angle addresses how history can contribute to understanding (a) translation, understood as product or discourse, as process or activity, and as function or the role it plays in cultural systems, and (b) reflections on translation and how they vary across time. By focusing on this second angle, the contributions included in this special issue collectively aim to bring together different Eastern and Western views on the role of history to understand both translation and translation studies.

All papers center on translation understood as an intentional phenomenon of human and mostly intercultural communication, and on the role played by translation in Eastern and Western cultural practices and encounters. They range from translation between Asian and European languages, by dealing with Chinese, Japanese, Korean, Tagalog, Turkish, English, Flemish, Spanish and Portuguese languages, but they mostly focus on the translation of cultures, social structures and identities and on the (re)creation of stereotypes and images of Otherness. Accordingly, they consider both situations where Eastern and Western works are disseminated in different times, places, languages and cultures, as well as the phenomenon of "cultural translation", which occurs in cases where cultural agents travel in space to encounter different cultures and report on such Otherness by means, for example, of travel writing. In all these cases the negotiation of identities, presuppositions, ideologies and perceptions is the key to understanding the role of translation in the dynamics of cultures. This follows one of the well-known tenets of descriptive approaches in Translation Studies, as stated by Theo Hermans: 
If it were a matter of technical code-switching only, translation would be as exciting as a photocopier. Translation is of interest because it offers first-hand evidence of the prejudice of perception. Cultures, communities and groups construe their sense of self in relation to others and by regulating the channels of contact with the outside world. In other words, the normative apparatus which governs the selection, production and reception of translation, together with the way translation is conceptualized at certain moments, provides us with an index of cultural self-definition. (Hermans 1999: 95)

Translation is therefore understood not only as a mere operation of interlingual "code-switching". It is more encompassing in that it is addressed as a channel of contact with other cultures or "the outside world". Even if in practice it is mostly associated to interlingual communication, it is an indirect channel of contact between cultures since translation is a result of mediation by several agents involved in the selection, production and reception processes governed by cultural specific norms. Thus understood, translation becomes relevant as a means to the study of various processes of contact and transfer between cultures. To study translation is then to study the historically variable influence of other cultures upon a receiving or target culture, either because intercultural contacts begin or cease to take place or because they increase or decrease or take up different profiles across time. Last but certainly not least, to study translation is also to study "cultural selfdefinition" in that translation reveals how a culture defines itself by means of the intercultural relations it establishes but also by means of how the relations are established, fostered, or silenced. It does not come as a surprise that the author goes on to state that in the process of intercultural communication by means of translation: "[i]t would be only a mild exaggeration to claim that translation tells us more about those who translate and their clients than about the corresponding source text" (Hermans 1999: 95), given that so much of it is influenced by the target context, culture, situation and the decisions of agents. To map translation and to understand its main trends and periods, to follow reflection upon translation, translation theory, methods and historiography across time, to study the profiles of translators, editors, clients, patrons, among other intercultural mediators, and to identify, describe and attempt to understand and explain configurations of identities in East and West encounters across time, all this becomes instrumental in understanding the source and mostly the receiving cultures. By embodying culture specific target norms, translations "project the underlying value systems into their representations of the source text" and cultural Otherness, one might add (Hermans 1999: 95).

This issue encompasses several ways of studying translation history. The first three papers present future or ongoing research projects addressing the history of translation; the last three papers offer case studies on $17^{\text {th }}, 18^{\text {th }} 19^{\text {th }}$ and $20^{\text {th }}$ century examples of East and West encounters in translation. The first paper by Teresa Seruya offers a mainly metahistoriographic prospective reflection on how to write a history of translation. As one of the coordinators of the research project on the 
archaeology of translation entitled Intercultural Literature in Portugal (1930-2000): A Critical Bibliography (UCP-CECC and UL-CEAUL 2009), the author is clearly interested in designing a project that uses this mapping of literary works translated and published in Portugal along with other mappings of translation in Portugal as a stepping stone for a more ambitious project of writing a History of Translation in Portugal. In order to prepare and implement this historiographic project, this paper addresses issues such as the definition of the object (assumed translation) and a time frame, as well as the definition of concepts such as historical fact, progress, evolution, change, causation, purpose, explanation or periodization. In doing so, it illustrates these issues with examples drawn from research on translation and it ends with suggestions and recommendations for implementing a history of translation in Portugal.

Ken Takiguchi's paper offers a retrospective description of the inter-Asian negotiations in translations of Shakespeare included in the database $\mathrm{A}|\mathrm{S}| \mathrm{I} \mid \mathrm{A}$. This paper makes good use of corpus translations included in the multilingual online digital archive entitled Asian Shakespeare Intercultural Archive $(\mathrm{A}|\mathrm{S}| \mathrm{I} \mid \mathrm{A})$, and attempts to surpass the habitual binarism of East and West comparisons to zoom in on how the traditional performance style adopted in the 2009 Korean translation of Shakespeare's Romeo and Juliet, by the National Changgeuk Company of Korea, was negotiated in its translation into Japanese produced by the $\mathrm{A}|\mathrm{S}| \mathrm{I} \mid \mathrm{A}$ team. Addressing the issues of colonialism and post-colonialism in East Asia, the author debunks the stereotype of a homogenous "Asian" translation tradition by offering a case study of how Romeo and Juliet was translated differently under the influence of two East Asian translation traditions: Korean and Japanese.

Marta Pacheco Pinto takes up a different view upon studying translation across time by focusing on the relevance of paratexts on literary translation as sources for information on translation from Eastern languages and cultures, such as Chinese and Japanese, into Portuguese and presents a potential project for an anthology of paratexts on translating the Far East in the Far West. Similar anthologies of mostly normative and prescriptive reflections and preferred translation strategies included in paratexts to published translations tend to focus on central or hypercentral European languages and literatures, leaving aside less translated ones. This project is illustrated by a case study on the reflections by Camilo Pessanha (1867-1926), a Portuguese symbolist poet, included in the preface to his translation of Ming Dynasty elegies, published 1914 in Macau.

Marlon James Sales offers a comparative analysis of $17^{\text {th }}$ to $19^{\text {th }}$ century Castilian and Tagalog, the most studied Philippine language, to zoom in on how Spanish missionaries negotiated Tagalog's profuse cues of verbal politeness with the aim of using autochthonous languages to evangelize the Indios. Focusing on Tagalog politeness markers expressing reverence, this paper addresses the way Spanish lexicographers and grammarians attempted to identify its sociocultural values so as to choose the most likely lexical candidates for translation into Spanish, resorting to the politeness rules of the target language. The relevance of contextual variables such as power and age is considered to 
understand how the symmetrical use of politeness cues in Tagalog is translated into an asymmetrical use in Spanish, which is overtly expressive of the colonial power structure, as well as to understand how a form expressing courteous affection and respect towards and addressee of high social status and nobility was used to translate the prayer "Hail Mary" into Tagalog. According to the author, its survival in the contemporary prayer disregards language change and remains a witness to the power structure of a colonial past.

Audrey Heijns chooses to analyze different images and stereotypes of the Chinese and of a Chinese city, Guangzhou, configured in three $19^{\text {th }}$-century Dutch examples of travel writing. The reflections upon three different views on this Chinese city as examples of cultural translation range from an imperialist and domesticating stance to an anti-imperialist and exoticizing one. The analysis of such view enables the author to conclude that just as the Otherness and Foreignness of this city is described and recreated so the individual profile of each Dutch traveler and writer is also strongly imprinted in each text. This merging makes the Eastern Otherness thus depicted appear superior or inferior (in an orientalizing translation style) or also (in an appropriative translation style) universally equal to and indistinct from the Western identities of the observing Selves, whose cultural self-definition, perception and knowledge (as well as their presuppositions about their target readers) are therefore revealed by their views on the culturally different East.

Swansan A. Aljahdali considers the English, Arabic and Turkish translations of Paulo Coelho's Brazilian Portuguese bestselling novel, O Alquimista, in order to perform a functionalist reading of the recreated narrative structures aimed at different readers located in what the author identifies as three different contexts: Western, Eastern and Turkish. What the author calls a cross-cultural "rediscoursing" of the narrative is claimed to produce different narrative structures, different objects of interpersonal communication aimed at fostering good sales figures and appealing to popular taste. The analysis of selected examples leads the author to conclude that spirituality and secularism, individualism, and mysticism are reproduced or "re-discoursed" according to differing views and value systems of the target cultures, and this impinges on three different narrative structures united by an amicable interpersonal relation towards the various target readerships.

\section{Acknowledgments}

In the process of preparing this special issue, we received the generous help and inspiring insights from colleagues in different parts of the world, and especially we would like to express our gratitude for the constructive cooperation of Leo Chan, Bart Dessein, Lieven D'hulst, Daniel Gallimore, Hanne Jansen, Alexandra Lopes, Reine Meylaerts, Kent Ramos, Sehnaz Tahir-Gürçaglar, Jonathan Webster, Zhang Junfeng, Zhu Chunshen, and we would also like to thank Lau Tak On for his work on this issue. Their warm support is greatly appreciated. 
This special issue originated from the "East \& West Conference on Translation Studies - Translation History Matters", which was co-organized by the School of International Studies, Sun Yatsen University (SYSU), China and the School of Arts and Humanities, University of Lisbon (FLUL), Portugal and held at the SYSU Zhuhai Campus on 24-27 September 2013. The coconvenors were Huang Guowen (SYSU) and Alexandra Assis Rosa (FLUL). Those who generously contributed to the organization of this Conference include Professor Wang Bin and Dr Xie Guixia of SYSU and Dr Hermenegildo Fernandes of FLUL. The members of the Scientific Committee of the Conference were Huang Guowen (co-Chair), Alexandra Assis Rosa (co-Chair), Leo Tak-hung Chan, Luo Xuanming, Anthony Pym, Teresa Seruya, and Wang Dongfeng.

After the Conference an open call for papers was made public and quite a number of papers were then submitted. With the help of the reviewers and the editors of the Journal of World Languages, this special issue was finally completed. We would like to express our gratitude to the general editors of the Journal of World Languages, to all contributors for their generous support and constructive cooperation and especially to authors who entrusted us with their work and provided full cooperation throughout the editing process.

\section{References}

D’Hulst, Lieven. 2010. “Translation History.” In Handbook of Translation Studies, edited by Yves Gambier and Luc van Doorlaer, 397-405. Amsterdam: John Benjamins.

Hermans, Theo. 1999. Translation in Systems. Descriptive and System-oriented Approaches Explained. Manchester: St. Jerome.

Universidade Católica Portuguesa, Centro de Estudos de Comunicação e Cultura and Universidade de Lisboa, Centro de Estudos Anglísticos da Universidade de Lisboa. 2009. Intercultural Literature in Portugal (1930-2000): A Critical Bibliography. Lisboa: CECC, CEAUL. http://www.translatedliteratureportugal.org/. 